\title{
COMPARISON OF FENTANYL AND DEXMEDETOMIDINE AS AN ADJUVANT TO BUPIVACAINE IN SUPRACLAVICULAR BRACHIAL PLEXUS BLOCK: A RANDOMIZED-DOUBLE BLIND PROSPECTIVE STUDY
}

\author{
SWASTIKA SWARO*, DAISY KARAN, SWARNA BANERJEE
}

Department of Anaesthesiology, IMS and SUM Hospital, Bhubaneswar, Odisha, India. Email: drswastika81@yahoo.com Received: 30 March 2016, Revised and Accepted: 05 May 2016

\section{ABSTRACT}

Objectives: Supraclavicular block of brachial plexus provides complete and reliable anesthesia for upper limb surgeries. Using adjuvant to local anesthetics, blocks can be prolonged to long durations. Peripheral nerve blocks thus help in avoiding the hazards of general anesthesia. We compared the sensory blockade, motor blockade, and duration of analgesia with the addition of fentanyl or dexmedetomidine to bupivacaine for supraclavicular brachial plexus block.

Methods: A total of 50 American Society of Anesthesiologist's Physical Status I and II patients scheduled for elective upper limb surgeries under supraclavicular brachial plexus block were divided into two equal groups in a randomized double-blinded fashion. Group BF received $30 \mathrm{ml}$ bupivacaine with fentanyl $50 \mu \mathrm{g}$ and Group BD received $30 \mathrm{ml}$ bupivacaine with dexmedetomidine $50 \mu \mathrm{g}$. The characteristics for anesthesia and analgesia were assessed in both groups.

Results: Duration of sensory and motor block was $363.4 \pm 38.36$ minutes and $357 \pm 36.77$ minutes, respectively, in Group BF while it was $452.96 \pm 77.12$ minutes and $441.52 \pm 48.46$ minutes in Group BD. There was a statistically significant difference in onset of sensory and motor block between the two groups. The duration of analgesia (time to requirement of rescue analgesia) in Group BD was longer than in Group BF (471.44 \pm 65.88 minutes vs. $366.48 \pm 38.02$ minutes) with $(\mathrm{p}<0.0001)$. There were minimum hemodynamic disturbances and side effects in any group except for Grade 3 sedation score which was more in Group BD.

Conclusion: Dexmedetomidine, when added to bupivacaine in supraclavicular brachial plexus block, enhanced the duration of sensory and motor block and also the duration of analgesia, more than when fentanyl was added to bupivacaine.

Keywords: Fentanyl, Dexmedetomidine, Bupivacaine, Supraclavicular brachial block.

(C) 2016 The Authors. Published by Innovare Academic Sciences Pvt Ltd. This is an open access article under the CC BY license (http://creativecommons org/licenses/by/4. 0/) DOI: http://dx.doi.org/10.22159/ajpcr.2016.v9i5.11928

\section{INTRODUCTION}

Upper limb surgeries are usually done under peripheral blocks such as brachial plexus block. Reduced hospital stay, less financial burden, and avoidance of complications due to general anesthesia are many advantages of brachial plexus block in comparison to general anesthesia. Peripheral nerve blocks not only provide intraoperative anesthesia but also post-operative analgesia without any systemic side effects [1]. Different adjuvants are used with local anesthetics that prolong the duration of anesthesia with less adverse effects. Opioids, $\alpha 2$ agonist, and dexamethasone are few of them. Addition of fentanyl to local anesthetic is known to significantly improve the duration of sensory and motor blockade as well as visual analog scale scores [2,3]. Dexmedetomidine, a potent centrally acting $\alpha 2$ agonist, is widely used for anesthesia, analgesia, monitored anesthesia care, and as an adjuvant to local anesthetic for peripheral nerve block [4,5]. In humans, dexmedetomidine has shown to prolong the duration of the block and post-operative analgesia when added to local anesthetic in various regional blocks [6-9]. The purpose of the study was to examine if dexmedetomidine added to bupivacaine enhanced the duration of the motor block, sensory block, and duration of analgesia as compared to fentanyl in brachial plexus block, thus providing a better alternative to opioids.

\section{METHODS}

After obtaining ethical committee clearance and written informed consent from patients, a double-blinded randomized prospective clinical trial was carried out on 50 American Society of Anesthesiologist's Grades I and II patients of either sex aged 20-60 years, undergoing various orthopedic surgeries of upper limb under supraclavicular brachial plexus block. They were divided into two groups of 25 patients each. Patients with known hypersensitivity to local anesthetic drugs, bleeding disorders, pre-existing neuropathy, any hepatic, renal, neurological, psychiatric, or neuromuscular diseases, and pregnancy/ lactation were excluded from the study.

On arrival in the operation theater, baseline heart rate (HR), blood pressure, and saturation were recorded. An intravenous line (IV) was secured in the unaffected limb and ringers lactate was started. Injection ranitidine and injection midazolam $(0.03 \mathrm{mg} / \mathrm{kg})$ were given IV.

Patients were randomly assigned into two groups of 25 each. After aseptic preparation of the skin, supraclavicular plexus block was performed with the help of nerve stimulator locator. A 22 Gauge $30 \mathrm{~mm}$ insulated needle (Stimuplex, Braun, Germany) was attached to the locator and inserted at an initial current output of $1.5 \mathrm{~mA}$ and $2 \mathrm{~Hz}$ frequency. The location endpoint was a distal motor response with an output lower than $0.5 \mathrm{~mA}$ in the median nerve region. Following negative aspiration $30 \mathrm{ml}$, local anesthetic was injected. Group BF received $30 \mathrm{ml}$ of bupivacaine $0.5 \%$ with $50 \mu \mathrm{g}$ fentanyl and BD received $30 \mathrm{ml}$ of bupivacaine $0.5 \%$ with $50 \mu \mathrm{g}$ dexmedetomidine. A 3 minutes massage was performed to facilitate an even drug distribution.

Assessment of sensory block was done by pinprick method every minute after drug injection till complete sensory blockade was achieved in distribution of any one major nerve. Sensory onset was considered when there was dull sensation to pinprick, and the complete sensory block was considered when there was complete loss of sensation to pinprick. 
Sensory block was graded as:

- Grade 0: Sharp pain felt

- Grade 1: Analgesia, dull sensation felt

- Grade 2: Anesthesia, no sensation felt.

Assessment of motor block was evaluated using the modified Bromage scale. Onset of the block was considered when there was Grade 1i motor blockade and complete when Grade 2 block.

Motor block was graded as:

- Grade 0: Normal motor function with full flexion and extension of elbow wrist and fingers

- Grade 1: Decreased motor strength with ability to move fingers only

- Grade 2: Complete motor block with inability to move fingers.

The block was considered failed if any anesthesia was found to be inadequate in any major nerve distribution even after 30 minutes of drug injection and were excluded from the study.

The duration of sensory block was defined as the time interval between the end of the local anesthetic administration and the complete resolution of anesthesia of all nerves. The duration of motor block was defined as the time interval between the end of the local anesthetic administration and the recovery of complete motor function of the hand and forearm. Patients were assessed for pain as per numerical rating scale of 1-10. It was recorded every 60 minutes till score of 5 . Rescue analgesia was immediately administered (diclofenac sodium $1.5 \mathrm{mg} / \mathrm{kg}$ IV) at such point. Duration of analgesia was calculated from the time of sensory onset to first dose of rescue analgesia.

All patients were observed for any side effects such as nausea, vomiting, dryness of mouth, itching, sedation, side effects of block like respiratory distress due to pneumothorax, Horner's syndrome, and recurrent laryngeal nerve palsy. Hypotension was defined as fall in mean arterial pressure $>20 \%$ of baseline value and bradycardia when $H R \leq 50 /$ minutes This was corrected with $100 \mathrm{ml}$ fluid bolus or ephedrine $6 \mathrm{mg}$ if required and IV atropine $0.6 \mathrm{mg}$, respectively. Degree of sedation was monitored using Ramsay sedation scale (1: Awaken and alert, 2: Sedated but responding to mild physical stimuli, 3 : Sedated but responding to moderate or strong physical stimulus, and 4: Not arousable).

At the end of procedure, quality of anesthesia was graded as Grade IV (excellent) - no complaint from the patient; Grade III (good) - Minor complaint from the patient that did not require supplemental analgesics; Grade II (moderate) - Complaint that required supplemental analgesics; Grade I (unsuccessful) L - Patients required general anesthesia.

\section{RESULTS}

About 50 patients posted for upper limb surgeries were randomly divided into two groups, $\mathrm{BF}$ and $\mathrm{BD}$, of 25 each. Both groups were comparable in terms of age, gender, weight, and type of surgeries (p>0.001) (Table 1).

Onset of sensory block was faster in Group BD $(2.108 \pm 0.68$ minutes $)$ than in Group BF $(8.4 \pm 1.27$ minutes), with $\mathrm{p}<0.0001$ (Table 2). Onset of motor block was $9.088 \pm 1.81$ and $4.504 \pm 1.31$ minutes in Groups BF and $B D$, respectively $(\mathrm{p}<0.0001)$.

Duration of sensory block was $452.96 \pm 77.12$ minutes in Group BD as compared to $363.4 \pm 38.36$ minutes in Group BF. The duration of motor block was $441.52 \pm 48.46$ minutes in Group BD, whereas $357 \pm 36.77$ minutes in Group BF. Significantly longer duration of sensory and motor blockade was observed in Group BD than Group BF ( $p<0.0001)$ (Table 2).

There was significant increase in duration of analgesia in Group BD (471.44 \pm 65.88 minutes) as compared to Group BF $(366.48 \pm 38.02$ minutes), and the difference was statistically significant (Table 2) $(\mathrm{p}<0.0001)$
Quality of anesthesia was excellent in Group BD, 22 patients achieved Grade IV quality block and only 3 patients required sedation or sedation with analgesia, whereas in Group BF, 11 patients achieved Grade IV quality of block and 1 patient required general anesthesia due to inadequate block ( $\mathrm{p}=0.001$ ) (Table 3 ).

No episode of respiratory depression or hypoxemia was observed in any patients intraoperatively or $24 \mathrm{hrs}$ postoperatively. Bradycardia was found in 3 patients of Group BD and none in Group BF. Nausea and vomiting were found in 2 and 1 patient in Group BD and BF, respectively. Sedation score of 3 was most often noted in Group BD (15 patients) compared to Group BF, which was statistically significant $(\mathrm{p}=0.0001)$. Technical complications of the block such as hematoma, pneumothorax, and Horner's syndrome were not noted in any patient during the study (Table 4).

\section{Statistical analysis}

The data were analyzed by SPSS 20 software. Unpaired t-test was applied for demographic data, hemodynamic parameters, onset and duration of sensory and motor blockade, and duration of analgesia.

Table 1: Demographic data

\begin{tabular}{llll}
\hline Variables & $\mathbf{n = 2 5}$ & \multirow{2}{*}{$\mathbf{p}$} \\
\cline { 2 - 3 } & Group BF & Group BD & \\
\hline Age (years) & $34.68 \pm 8.70$ & $34.96 \pm 8.59$ & 0.909 \\
Sex (M/F) & $16 / 9$ & $19 / 6$ & \\
Weight (kg) & $56.08 \pm 4.57$ & $56.4 \pm 4.93$ & 0.813 \\
Type of operation & & & \\
$\quad$ Olecranon & 10 & 11 & \\
$\quad$ Lower end humerus & 9 & 7 & \\
Radius, ulna & 6 & 7 & \\
\hline
\end{tabular}

Values are expressed in mean \pm SD. n: Number of patients, M: Male, F: Female, Kg: Kilograms, SD: Standard deviation, BF: Bupivacaine with fentanyl, BD: Bupivacaine with dexmedetomidine

Table 2: Characteristics of blockade

\begin{tabular}{llll}
\hline & $\mathbf{n}=\mathbf{2 5}$ & $\mathbf{p}$ \\
\cline { 2 - 3 } & Group BF & Group BD & \\
\hline $\begin{array}{l}\text { Onset of sensory } \\
\text { block (minutes) }\end{array}$ & $8.4 \pm 1.27$ & $2.108 \pm 0.68$ & $<0.0001$ \\
$\begin{array}{l}\text { Duration of sensory } \\
\text { block (minutes) }\end{array}$ & $363.4 \pm 38.36$ & $452.96 \pm 77.12$ & $<0.0001$ \\
$\begin{array}{l}\text { Onset of motor } \\
\text { block (minutes) }\end{array}$ & $9.088 \pm 1.81$ & $4.504 \pm 1.31$ & $<0.0001$ \\
$\begin{array}{l}\text { Duration of motor } \\
\text { block (minutes) }\end{array}$ & $357 \pm 36.77$ & $441.52 \pm 48.46$ & $<0.0001$ \\
$\begin{array}{l}\text { Duration of } \\
\text { analgesia (minutes) }\end{array}$ & $366.48 \pm 38.02$ & $471.44 \pm 65.88$ & $<0.0001$ \\
\hline
\end{tabular}

Values are expressed in mean \pm SD. $n$ : Number of patients, SD: Standard deviation, BF: Bupivacaine with fentanyl, BD: Bupivacaine with dexmedetomidine

Table 3: Incidence of side effects

\begin{tabular}{llll}
\hline Side effects & $\mathbf{n}=\mathbf{2 5}$ & $\mathbf{p}$ \\
\cline { 2 - 3 } & Group BF & Group BD & \\
\hline Hypotension & 1 & - & 0.322 \\
Bradycardia & - & 3 & 0.076 \\
Sedation (Grade 3) & - & 15 & 0.0001 \\
Respiratory depression & - & - & \\
Nausea, vomiting & 2 & 1 & 0.56 \\
Pruritus & 1 & - & 0.322 \\
Pneumothorax & - & - & \\
Horner syndrome & - & - & \\
\hline BF: Bupivacaine with fentanyl, BD: Bupivacaine with dexmedetomidine
\end{tabular}

BF: Bupivacaine with fentanyl, BD: Bupivacaine with dexmedetomidine 
Table 4: Quality of block

\begin{tabular}{llll}
\hline Quality of block & $\mathbf{n = 2 5 ( \% )}$ & & \multirow{2}{*}{$\mathbf{p}$} \\
\cline { 2 - 3 } & Group BF & Group BD & \\
\hline Grade 1 & $1(4)$ & - & 0.001 \\
Grade 2 & $6(24)$ & $1(4)$ & \\
Grade 3 & $7(28)$ & $2(8)$ & \\
Grade 4 & $11(44)$ & $22(88)$ & \\
\hline
\end{tabular}

BF: Bupivacaine with fentanyl, BD: Bupivacaine with dexmedetomidine

Fisher exact test was applied for assessment of quality of block. p value was considered significant if $<0.05$ and highly significant if $<0.001$.

\section{DISCUSSION}

Brachial plexus block has proved to be a better alternative to general anesthesia for upper limb surgeries. With addition of adjuvant to local anesthetics block can be prolonged to cover lengthy surgeries. Out of all the available options, the $\alpha 2$ adrenergic receptor agonist-like clonidine and dexmedetomidine has proved to be better alternatives to other adjuvants such as opioids. Though addition of fentanyl enhances postoperative analgesia, the duration of this effect is too brief to be clinically useful which was stated Kardas et al. [11] and was in congruence with our observation. Karakaya et al. [12] observed that $100 \mu \mathrm{g} / \mathrm{kg}$ fentanyl added in axillary brachial plexus produced no difference in block characteristics of bupivacaine $0.25 \%$ and increased the incidence of side effects such as nausea and vomiting, though post-operative analgesia was doubled. Supportive observation in increase in duration of sensory and motor block with post-operative analgesia has also been observed in studies by Geze et al. [13], Madhusudan et al. [2], Sindjelic et al. [14], and Chavan et al. [15]. In 2000, Nisikawa et al. found that addition of fentanyl to axillary blocks with lidocaine plus epinephrine increase block duration by approximately $1 \mathrm{hr}$ but delayed block onset in all branches. It was speculated that this delay in onset of action of fentanyl was caused by differences in $\mathrm{pH}$ of the injectates [3].

Various studies were done with clonidine as adjuvant to the local anesthetic. El Saied et al. conducted a study, in which axillary brachial plexus blockade was performed with addition of clonidine to ropivacaine [16]. The study showed that addition resulted in prolongation of sensory and motor block and analgesia without increased incidence of side effects. In another study, Cucchiaro and Ganesh evaluated the effects of clonidine on the duration of sensory and motor block and analgesia in children in various peripheral nerve blocks including brachial block and concluded that addition of clonidine to either bupivacaine or ropivacaine can extend sensory and motor blocks [17]. Dexmedetomidine, an $\alpha 2$ adrenergic receptor agonist, acts like clonidine. It is highly specific and selective to $\alpha 2$ receptors. It has been successfully utilized in various anesthetic techniques due to hemodynamic stabilizing properties, sedative, analgesic, and sympatholytic effects [18]. Highly lipophilic nature of dexmedetomidine allows rapid absorption into the cerebrospinal fluid and binding to $\alpha 2$ receptors of the spinal cord for its analgesic action.

The action of dexmedetomidine on the $\alpha 2$ receptors in the locus coeruleus and dorsal horn of spinal cord reduces central sympatholytic output, resulting in increased firing of inhibitory neurons, and hence, producing analgesia is a known feature. Peripheral $\alpha 2$ receptors may also provide antinociception. The inhibitory action of $\alpha 2$ receptor agonist is expressed by hyperpolarization of cell membrane and decreased firing of excitable cells of the central nervous system. Reduction of calcium conductance into cells, thus inhibiting neurotransmitter release is other prominent physiologic actions ascribed to $\alpha 2$ adrenoceptors. The nerve is prevented from firing, and it also prevents propagation of signals to the neighbors, providing analgesia in two different ways [19-21]. Peripheral analgesic [22] action of dexmedetomidine is due to its binding to $\alpha 2 \mathrm{~A}$ adrenergic receptor.
Marhofer et al. reported a profound prolongation of ulnar nerve block (UNB) of $60 \%$ with perineural dexmedetomidine when added to $0.75 \%$ ropivacaine, whereas systemic administration of $20 \mu \mathrm{g}$ dexmedetomidine resulted in a prolongation of only $10 \%$ during UNB with $0.75 \%$ ropivacaine [23]. Esmaoglu et al. added dexmedetomidine to levobupivacaine for axillary brachial plexus block and showed that it shortens the onset time of both motor and sensory block, prolongs the duration of block and the duration of post-operative analgesia [8]. Agarwal et al. compared the effects of adding dexmedetomidine to bupivacaine in supraclavicular brachial plexus block in 50 patients [24] They concluded that dexmedetomidine added as an adjuvant to bupivacaine for supraclavicular brachial plexus block significantly shortens the onset time and prolongs the duration motor and sensory block and duration of analgesia. Patients in dexmedetomidine group were adequately sedated with no adverse effects except bradycardia in one. It coincides with the result of our study. Memis et al. in their study showed that addition of dexmedetomidine to lignocaine for IV regional anesthesia improves both qualities of anesthesia as well as intraoperative and post-operative analgesia [7].

The present study is a randomized double-blinded study, where we compared addition of injection fentanyl $50 \mu \mathrm{g}$ and dexmedetomidine $50 \mu \mathrm{g}$ to bupivacaine in supraclavicular brachial plexus block and found that that there was significantly increased the duration of sensory and motor blockade in the dexmedetomidine group than the fentanyl group. In our study, 22 patients (88\%) in Group, BD achieved Grade 4 block, i.e., excellent block without any supplementary analgesia or sedation, whereas only 11 patients (44\%) in Group BF achieved Grade 4 quality. This improved quality of block might be the result of various mechanisms of nerve conduction block such as hyperpolarization [25], decreased CAP [26], and inhibition of voltage-gated sodium pump by dexmedetomidine. A significant prolongation in surgical anesthetic and analgesic duration in patients receiving adjuvant - dexmedetomidine as observed in our study, lend support to various studies by Ammar and Mahmoud [4], Esmaoglu et al., [8] Gandhi et al., [27] and Kathuria et al. [28] with the use of dexmedetomidine in dose ranging from 50 to $100 \mu \mathrm{g}$.

Hemodynamic parameters were similar in all groups. No respiratory depression, fall in $\mathrm{SpO}_{2}$ was observed in any patient of either study groups. Hypotension was noted in one patient in Group BF, bradycardia in 3 patients of Group BD. This negative chronotropic effect of dexmedetomidine did not require any anticholinergic drug therapy. Abdallah and Brull in the meta-analysis of perineural application of dexmedetomidine as a local anesthetic adjuvant stated that dexmedetomidine produced reversible bradycardia in $7 \%$ of brachial plexus block patients with no incidence of hypotension [29] Incidence of nausea and vomiting were 2 in Group BF versus 1 in BD group. Itching was observed in 1 patients receiving fentanyl as adjuvant. It is unlikely to have systemic side effects with perineural administration of drugs, but the systemic absorption of the drug may have a central effect. Side effect profile of both groups did not exhibit any significant difference. None of the patients in Group BD required sedation intraoperatively, and they were comfortable throughout the surgery with arousable sedative effects and it resolved with the recession of block. Achievement of score 3 sedation with the lack of hemodynamic or any other side effect, can make $50 \mu \mathrm{g}$ dexmedetomidine an attractive choice for supraclavicular brachial plexus block.

From this study, we would like to suggest that dexmedetomidine can be safely used with local anesthetics in various peripheral nerve blocks; however, further studies required to know the exact dose and any neurotoxic effect on the human nerve.

\section{CONCLUSION}

To conclude, we would like to state that dexmedetomidine besides shortening the onset time of block, prolongs the duration of sensory and motor block, post-operative analgesia and enhances the quality of block as compared with fentanyl when used as an adjuvant to bupivacaine in supraclavicular brachial plexus block without any significant side effect. 


\section{REFERENCES}

1. Murphy DB, McCartney CJ, Chan VW. Novel analgesic adjuvan for brachial plexus block: A systemic review. Anesth Analg 2000;90(5):1122-8

2. Madhusudan R, Kumar K, Kumar R, Potli S, Karthik D, Kapil M. Supraclavicular brachial plexus block with $0.75 \%$ ropivacaine and with additives tramadol, fentanyl - A comparative pilot study. Int J Biol Med Res 2011;2(4):1061-3.

3. Nishikawa K, Kanaya N, Nakayama M, Igarashi $M$, Tsunoda K, Namiki A. Fentanyl improves analgesia but prolongs the onset of axillary brachial plexus block by peripheral mechanism. Anesth Analg 2000;91(2):384-7.

4. Ammar AS, Mahmoud KM. Ultrasound-guided single injection infraclavicular brachial plexus block using bupivacaine alone or combined with dexmedetomidine for pain control in upper limb surgery: A prospective randomized controlled trial. Saudi J Anaesth 2012;6(2):109-14

5. Swami SS, Keniya VM, Ladi SD, Rao R. Comparison of dexmedetomidine and clonidine (a2 agonist drugs) as an adjuvant to local anaesthesia in supraclavicular brachial plexus block: A randomised double-blind prospective study. Indian J Anaesth 2012;56(3):243-9.

6. Kanazi GE, Aouad MT, Jabbour-Khoury SI, Al Jazzar MD, Alameddine MM, Al-Yaman R, et al. Effect of low-dose dexmedetomidine or clonidine on the characteristics of bupivacaine spinal block. Acta Anaesthesiol Scand 2006;50(2):222-7.

7. Memis D, Turan A, Karamanlioglu B, Pamukçu Z, Kurt I. Adding dexmedetomidine to lidocaine for intravenous regional anesthesia. Anesth Analg 2004;98(3):835-40.

8. Esmaoglu A, Yegenoglu F, Akin A, Turk CY. Dexmedetomidine added to levobupivacaine prolongs axillary brachial plexus block. Anesth Analg 2010;111(6):1548-51.

9. Obayah GM, Refaie A, Aboushanab O, Ibraheem N, Abdelazees M. Addition of dexmedetomidine to bupivacaine for greater palatine nerve block prolongs postoperative analgesia after cleft palate repair. Eur J Anaesthesiol 2010;27(3):280-4.

10. Ramsay MA, Savage TM, Simpson BR, Godwin R. Controlled sedation with alphaxolone-alphadolone. Br Med J 1974;2(5920):656-9.

11. Kardas K, Schools A, Concepcion M. Effect of brachial plexus fentanyl on supraclavicular block. A randomized, double-blind study. Reg Anaesth 1996;20(4):311-5.

12. Karakaya D, Buyukgoz F, Baris S, Guldogus F, Tur A. Addition of fentanyl to bupivacaine prolongs anaesthesia and analgesia in axillary brachial plexus block. Reg Anesth Pain Med 2001;26(5):434-8.

13. Geze S, Ulusoy H, Ertürk E, Cekic B, Arduc C. Comparison of local anaesthetic mixtures of tramadol or fentanyl for axillary plexus block in orthopaedic upper limb surgery. Eur J Gen Med 2012;9(2):118-23.

14. Sindjelic RP, Vlajkovic GP, Davidovic LB, Markovic DZ, Markovic MD. The addition of fentanyl to local anaesthetics affects the quality and duration cervical plexus block: A randomized controlled trial. Anaesth Analg 2010;111(1):234-7.

15. Chavan SG, Koshire AR, Panbude P. Effect of addition of

fentanyllocal anesthetic in brachial plexus block on duration of analgesia. Anesth Essays Res 2011;5(1):39-42.

16. El Saied AH, Steyn MP, Ansermino JM. Clonidine prolongs the effect of ropivacaine for axillary brachial plexus blockade. Can J Anaesth 2000;47(10):962-7.

17. Cucchiaro G, Ganesh A. The effects of clonidine on postoperative analgesia after peripheral nerve blockade in children. Anesth Analg 2007;104(3):532-7.

18. Khan ZP, Ferguson CN, Jones RM. Alpha-2 and imidazoline receptor agonists. Their pharmacology and therapeutic role. Anaesthesia 1999;54(2):146-65.

19. Kaygusuz K, Kol IO, Duger C, Gursoy S, Ozturk H, Kayacan U, et al. Effects of adding dexmedetomidine to levobupivacaine in axillary brachial plexus block. Curr Ther Res Clin Exp 2012;73(3):103-11.

20. Das A, Majumdar S, Halder S, Chattopadhyay S, Pal S, Kundu R, et al. Effect of dexmedetomidine as adjuvant in ropivacaine-induced supraclavicular brachial plexus block: A prospective, double-blinded and randomized controlled study. Saudi J Anaesth 2014;8 Suppl 1:S72-7.

21. Zhang Y, Chang-Song W, Jing-Hui S, Sun B, Shu-Jie L, Li P, et al. Perineural administration of dexmedetomidine in combination with ropivacaine prolongs axillary brachial plexus block. Int J Clin Exp Med 2014;7(3):680-5.

22. Yoshitomi T, Kohjitani A, Maeda S, Higuchi H, Shimada M, Miyawaki T. Dexmedetomidine enhances the local anesthetic action of lidocaine via an alpha-2A adrenoceptor. Anesth Analg 2008;107(1):96-101.

23. Marhofer D, Kettner SC, Marhofer P, Pils S, Weber M, Zeitlinger M. Dexmedetomidine as an adjuvant to ropivacaine prolongs peripheral nerve block: A volunteer study. Br J Anaesth 2013;110(3):438-42.

24. Agarwal S, Aggarwal R, Gupta P. Dexmedetomidine prolongs the effect of bupivacaine in supraclavicular brachial plexus block. J Anaesthesiol Clin Pharmacol 2014;30(1):36-40.

25. Pöpping DM, Elia N, Marret E, Wenk M, Tramèr MR. Clonidine as an adjuvant to local anesthetics for peripheral nerve and plexus blocks: A meta-analysis of randomized trials. Anesthesiology 2009;111(2):406-15.

26. Kosugi T, Mizuta K, Fujita T, Nakashima M, Kumamoto E. High concentrations of dexmedetomidine inhibit compound action potential in frog sciatic nerve without $\alpha 2$ adrenoceptor activation. Br J Pharmacol 2010;160(7):1662-76

27. Gandhi R, Shah A, Patel I. Use of dexmedetomidine along with bupivacaine for brachial plexus block. Natl J Med Res 2012;2(1):67-9.

28. Kathuria S, Gupta S, Dhawan I. Dexmedetomidine as an adjuvant to ropivacaine in supraclavicular brachial plexus block. Saudi J Anaesth 2015;9(2):148-54.

29. Abdallah FW, Brull R. Facilitatory effect of perineural dexmedetomidine on neuraxial and peripheral nerve block. A systemic review and metaanalysis. Br J Anaesth 2013;110(6):915-25. 